Mise en évidence de l'activité phosphatasique acide en microscopie électronique dans les cellules du méristème radiculaire d'Allium cepa

\author{
E. MIKULSKA et B. GABARA
}

La présence de la phosphatase acide dans les sphérosomes a été mise en évidence en microscopie photonique par Wałek-Czernecka (1962, 1965), O lszew ska et coll. (1963, 1964), Górska-Brylas s (1965), K wiatkowska (1966) et Pa lczewska (1966).

Matile et coll. (1965), Baltz (1966), Semadeni (1967) ont trouvé l'activité phosphatasique acide dans les sphérosomes isolés des plantules de Zea et Nicotiana.

Afin de confirmer ces constatations, nous avons cherché à localiser cette enzyme à l'aide du microscope électronique.

\title{
MATÉRIEL ET MÉTHODES
}

Nos observations ont porté sur le méristème radiculaire d'Allium cepa. Des petits fragments des racines, privées de coiffes, ont été fixés en $\mathrm{OsO}_{4}$ à $2 \%$ (d'après $\mathrm{P}$ a l a d e). La réaction décelant l'activité phosphatasique acide au microscope photonique et au microscope électronique a été effectuée sur le matériel fixé à froid par le liquide de Baker additionné de saccharose à 7,5\%. L'activité phosphatasique a été mise en évidence par la technique de Gomori, modifiée par Holt et $\mathrm{Hicks}$ (1961). Des incubations témoins ont été réalisées dans des milieux dépourvus de substrat. Le matériel destiné au microscope électronique a été ensuite postfixé dans $\mathrm{OsO}_{4}$ à $1 \%$ et inclus dans un mélange des méthacrylates.

Nous nous sommes servi de microscope électronique Tesla BS 242 .

\section{RÉSULTATS ET DISCUSSION}

$\mathrm{Au}$ miscroscope électronique le diamètre des sphérosomes varie de 0,4 à $0,9 \mu$. Ils sont entourés d'une simple membrane. Leur contour est rond, ou irrégulier. Leur intérieur montre une structure fine, granulaire, dense aux électrons (pl. I, fig. 1, 2, 3). 
Des nombreuses mitochondries, d'un diamètre de 0,4 à $0,9 \mu$, présentent un système tubulaire bien développé (pl. I, fig, 1, 2, 3). A côté des sphérosomes et mitochondries, on rencontre des formations osmiophiles, opaques aux électrons, aux contours irréguliers, étoilés (pl. I, fig. 2). Le réticulum endoplasmique apparaît sous forme de canaux, ou bien sous forme vésiculouse (pl. I, fig. 1, 2, 3).

$\mathrm{Au}$ miscroscope photonique le produit de la réaction décelant l'activité phosphatasique acide est localisé au niveau de granulations d'un diamètre de 0,4 à $0,8 \mu$ (pl. II, fig. 1$)$.

$\mathrm{Au}$ miscroscope électronique le produit de cette reaction enzymatique se laisse constater sur les bords des sphérosomes. Il est présent soit sous forme de précipité des fins granules (pl. II, fig. 5 et 6 ), soit sous forme des dépôts des gros grains (pl. II, fig. 2, 3, 4, 7). Certains sphérosomes montrent la même structure caractéristique qu'après la fixation par $\mathrm{OsO}_{4}$, les autres apparaissent comme homogènes (ce qui est probablement dû à la fixation au liquide de Baker).

Les canaux du réticulum endoplasmique montrent aussi une activité phosphatasique acide (pl. II, fig. 4, 6, 7).

Dans les coupes témoins les fins granules du précipité sont disposées uniformément, de façon peu caractéristique (pl. II, fig. 8). Il en résulte que le précipité constaté sur les bords des sphérosomes et à l'intérieur des canaux du réticulum endoplasmique est spécifique des sites de l'activité phosphatasique acide.

P oux (1966) a décelé au microscope électronique une autre enzyme caractéristique des sphérosomes (Olszewska et $\mathrm{Gabara}, 1964$; W a ł e k-Czernecka, 1965), et notamment l'aryl-sulphatase. L'activité de cette enzyme, à côté des sphérosomes, est localisée à l'intérieur des canaux du réticulum endoplasmique ( $\mathrm{P}$ o u x, 1966).

Quant à l'ultrastructure des sphérosomes, il paraît qu'elle dépend de l'espèce étudiée, ainsi que des méthodes employées. Les sphérosomes trouvés dans l'épiderme des écailles bulbaires d'Allium cepa par P eveling (1962) sont de même aspect que dans notre matériel (méristème radiculaire de la même espèce).

Notons que dans les cellules végétales les sphérosomes et le réticulum endoplasmique ne présentent pas sites uniques de l'activité phosphatasique acide. Elle a été constatée dans tous les éléments goldiens, dans les vacuoles (Poux, 1963a), ainsi que dans les grains d'aleurone des graines mises à germer ( $\mathrm{P}$ o u x, 1963b, 1965).

\section{RÉSUMÉ}

La méthode de Gomori appliquée sur les cellules du méristème radiculaire d'Allium cepa a révélé au miscroscope photonique, ainsi qu'au microscope électronique la présence de l'activité phosphatasique acide au niveau de sphérosomes. 


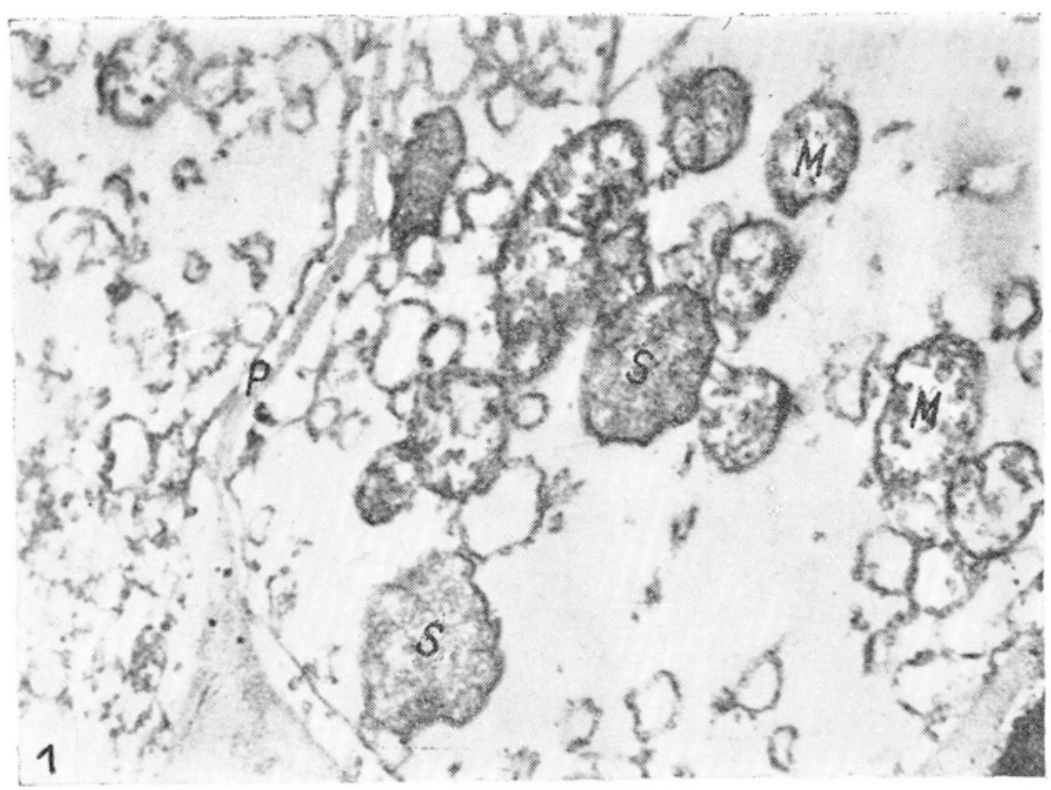

की

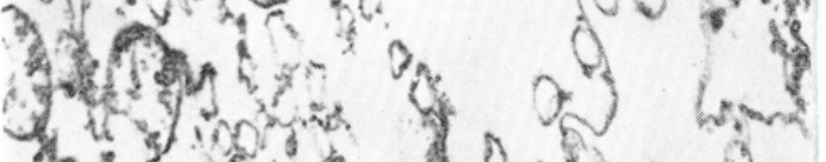

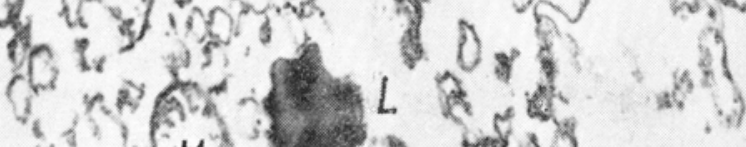

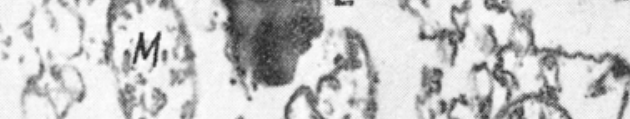
U. CDER I D M

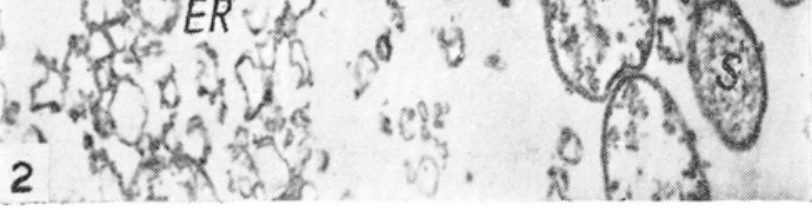

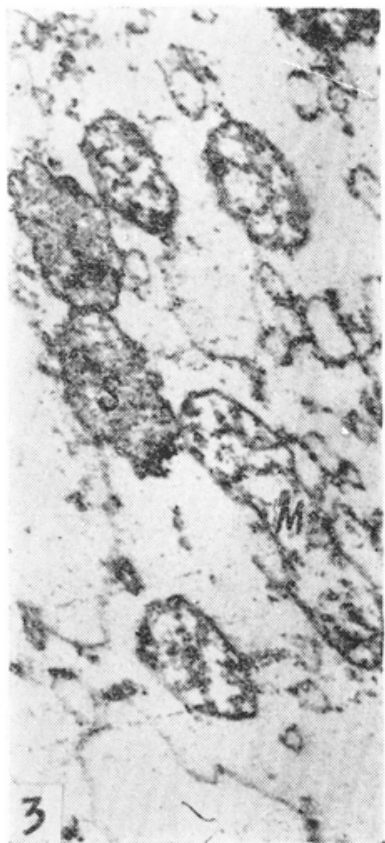

Cellules du méristème radiculaire d'Allium cepa; fix. $\mathrm{OsO}_{4}$ à $2 \% . S-$ sphérosomes, $M$ - mitochondries, $L$ - inclusions lipidiques, $E R$ - réticulum endoplasmique, $P-$ paroi cellulaire. Agrand. env. $12000 \times$. 

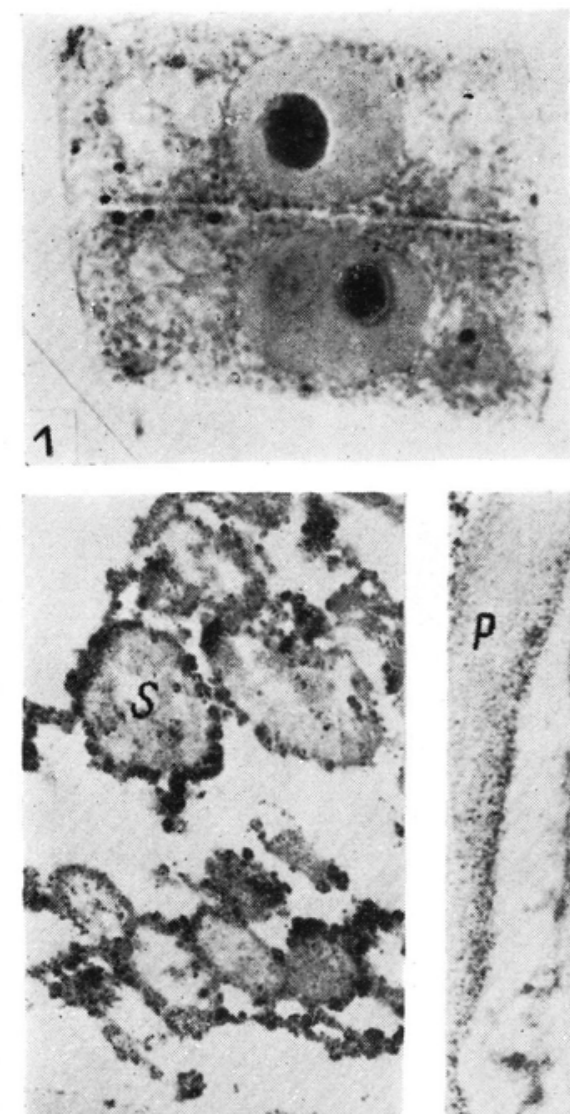

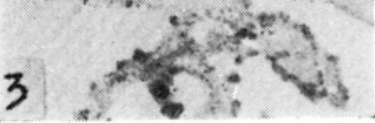

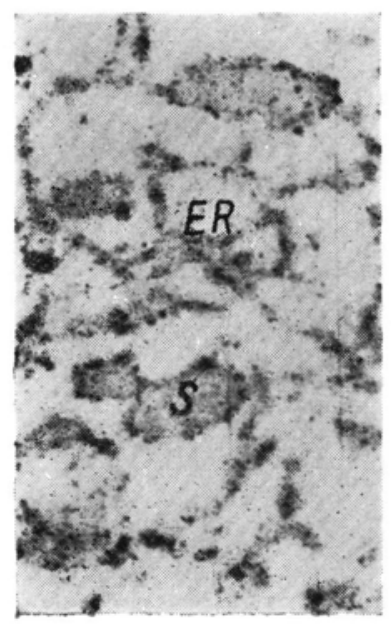

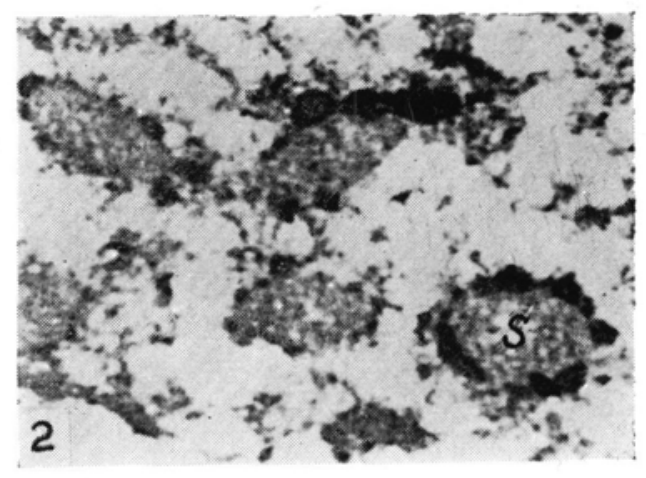
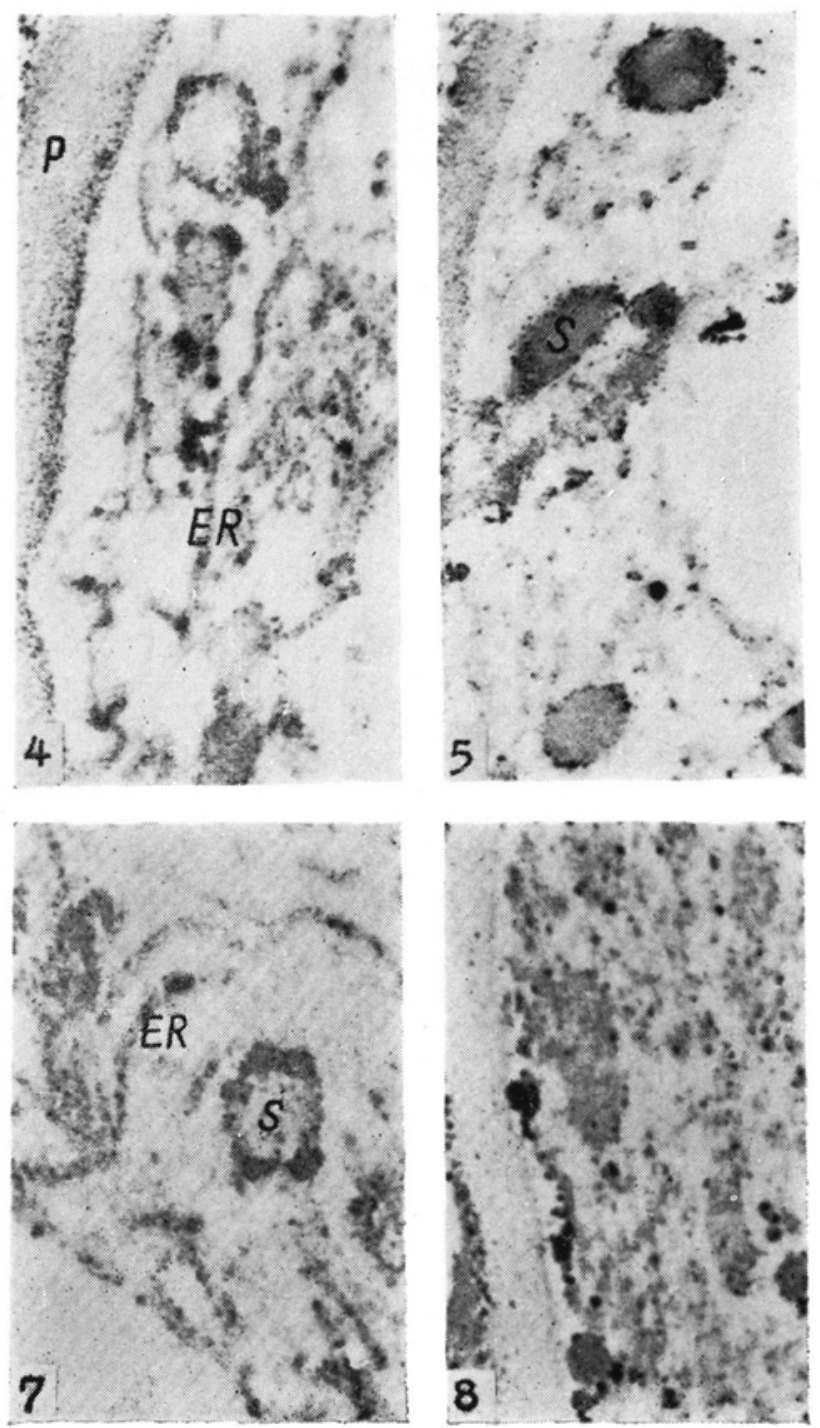
En outre, on a mis en évidence au microscope électronique d'activité phosphatasique acide à l'intérieur des canaux du réticulum endoplasmique.

Nous tenons à remercier M. le Professeur B. Z a bło cki, directeur du Laboratoire de Microbiologie de l'Université de Łódź, d'avoir mis à notre disposition le microscope électronique, ainsi que M. W. Udut pour son assistance technique.

Laboratoire de Cytochimie, Université de Łódź,

(Reçu: 2.IX.1967.)

Łódź, Nowotki 18, Pologne

\section{BIBLIOGRAPHIE}

B a ltz H. P., 1966, Intrazelluläre Lokalisation und Funktion von hydrolytischen Enzymen bei Tabak, Planta 70:207-236.

Górska-Brylass A., 1965, Hydrolases in pollen grains and pollen tubes, Acta Soc. Bot. Pol. 34:589-604.

Holt S. J., Hicks M., 1961, The localization of acid phosphatase in rat liver cells as revealed by combined cytochemical staining and electron microscopy, J. Bioph. Biochem. Cytology. 11:47-66.

Kwi a tk owsk a M., 1966, Z badań nad elajoplastami. Ornithogalum umbellatum cz. I. Obserwacje morfologiczne, cytochemiczne i cytoenzymatyczne, Acta Soc. Bot. Pol. 35:7-16.

Matile Ph., Baltz J. P., Semadeni E., Jost M., 1965, Isolation of spherosomes with lysosome characteristics from seedlings, Z. Naturforsch. 20b:693-698.

Olszewska M. J., Gabara B., Ohde S., 1963, Méthode simple pour la préparation des méristèmes radiculaires permettant la détection cytochimique de certaines hydrolases, Acta Soc. Bot. Pol. 32:651-655.

O ls zewska M. I., G a b a r a B., 1964, Recherches cytochimiques sur la présence de certaines hydrolases au cours de la cytocinèse chez les plantes supérieures, Protoplasma 59:163-180.

\section{Planche II}

Localisation de l'activité phosphatasique acide dans le méristème radiculaire d'Allium cepa; fix. liquide de Baker additionné de saccharose à 7,5\%.

fig. 1. Réaction positive au niveau de sphérosomes; mitochondries (rondes et allongées) sont incolores. Agrand. env. $1000 \times$.

fig. 2, 3, 4, 7. Le précipité spécifique de gros grains de PbS sur les bords des sphérosomes indique la localisation de l'activité phosphatasique acide.

fig. 5, 6. Activité phosphatasique acide indiquée par la présence du précipité sous forme de fins grains sur les bords des sphérosomes.

fig. 4, 7. Activité phosphatasißue acide à l'intérieur des canaux deu réticulum endoplasmique.

fig. 8. Préparation témoin. Précipité non spécifique disposé uniformément au niveau de tous les structures cytoplasmiques.

Fig. 2-8 - agrand. env. $12000 \times$. 
P a l c ze w s k a I., 1966, Występowanie esteraz we włoskach gruczołowych i liściach Drosera rotundifolia, Acta Soc. Bot. Pol. 35:307-313.

P e veling E., 1962, Der elektronenmikroskopische Nachweis der Sphärosomen in den Epidermiszellen der Zwiebelschuppen von Allium cepa, Protoplasma 55: $429-435$.

P o u x N., 1963a, Localisation de la phosphatase acide dans les cellules méristèmatiques de blé (Triticum vulgare Vill), J. de Microscopic. 2:485-489.

P o u x N., 1963b, Localisation des phosphates et de la phosphatase acide dans les cellules des embryons de blé (Triticum vulgare Vill) lors de le germination, J. de Microscopic. 2:557-568.

Poux N., 1965, Localisation de l'activité phosphatasique acide et des phosphates dans les grains d'aleurone. I. Grains d'aleurone renfermant a la fois globoïdes et cristalloides, J. de Microscopic. 4:771-782.

S e m a den i E. G., 1967, Enzymatic characterization of lysosome equivalents (spherosomes) in corn seedlings, Planta 72:91-118.

W a łe k-Czarnecka A., 1962, Mise en évidence de la phosphatase acide (monophosphoestérase II) dans les sphérosomes des cellules épidermiques des écailles bulbaires d'Allium cepa, Acta Soc. Bot. Pol. 31:539-543.

W a kek-Czarneck a A., 1965, The histochemical demonstration of some hydrolytic enzymes in spherosomes of plant cells, Acta Soc. Bot. Pol. 34:573-588.

\section{Lokalizacja aktywności kwaśnej fosfatazy w komórkach merystematycznych korzenia Allium cepa L. obserwowana w mikroskopie elektronowym}

\section{Streszczenie}

Badania przeprowadzone w mikroskopie świetlnym i elektronowym, z zastosowaniem metody Gomoriego, wykazały, że aktywność kwaśnej fosfatazy w komórkach merystematycznych korzenia Allium cepa zlokalizowana jest w sferosomach. Obserwacje w mikroskopie elektronowym ujawniły również obecność aktywności kwaśnej fosfatazy w badanym materiale w kanałach endoplazmatycznego retikulum. 